Article

\title{
Green Synthesis of Hydrophobic Magnetite Nanoparticles Coated with Plant Extract and Their Application as Petroleum Oil Spill Collectors
}

\author{
Mahmood M. S. Abdullah 1,2®, Ayman M. Atta ${ }^{1, *}$, Hamad A. Allohedan ${ }^{1}$, \\ Hamad Z. Alkhathlan ${ }^{1}$, M. Khan ${ }^{1}$ and Abdelrahman O. Ezzat ${ }^{1}$ \\ 1 Department of Chemistry, College of Science, King Saud University, P.O. Box 2455, Riyadh 11451, Saudi \\ Arabia; altaiar90@yahoo.com (M.M.S.A.); hlohedan@ksu.edu.sa (H.A.A.); khathlan@ksu.edu.sa (H.Z.A.); \\ mkhan3@ksu.edu.sa (M.K.); ao_ezzat@yahoo.com (A.O.E.) \\ 2 Department of Chemistry, Faculty of Applied Science, University of Taiz, P.O. Box 4007, Taiz, Yemen \\ * Correspondence: aatta@ksu.edu.sa; Tel.: +966-056-155-7975
}

Received: 19 September 2018; Accepted: 18 October 2018; Published: 19 October 2018

\begin{abstract}
In this study, an easy, rapid and eco-friendly method was used successfully to synthesize the magnetite nanoparticles (MNPs). In order to fine-tune the synthesized MNPs for the collection of heavy crude oil spills, the particles' surface was modified with green hydrophobic biocomponents that were extracted from Anthemis pseudocotula (AP). The surface modified reaction carried with that of the MNPs in the presence of $n$-hexane extract (APH) resulted in the formation of APH-MNPs, while in the presence of chloroform extract (APC), resulted in APC-MNPs formation. The as-formed MNPs were thoroughly characterized using transmittance electron microscopy, X-ray powder diffraction, vibrating sample magnetometer and thermogravimetric analysis. The efficiency of the surface-modified MNPs for the collection of oil spills in the presence of an external magnetic field was evaluated by taking different ratios of MNPs:crude oil. From the analysis of the results, we found that the APH-MNPs particles have higher efficiency in the collection of heavy crude oil than the corresponding APC-MNPs.
\end{abstract}

Keywords: green synthesis; plant extract; Anthemis pseudocotula; magnetite nanoparticles; oil spill collectors

\section{Introduction}

Oil spills are one of the most severe marine environmental disasters, causing water pollution through the release of several hazardous chemicals into the environment. The removal of oil spills is expensive and costs billions of dollars [1-3]. There are many techniques that can be used to combat oil spills, including mechanical, bioremediation and chemical techniques [4]. Among these techniques, chemical means of separation have become one of the most common methods, where different polymers and copolymers are used to absorb, disperse or collect the spilled oil [5-7]. In addition to polymers, some ionic liquids, poly (ionic liquids) and surfactants have also been tested in recent years [8-11]. The removal of spilled oils by employing chemical collectors has become one of the most acceptable techniques because of its high efficiency and ability to reuse the chemicals as compared with other methods such as oil spill sorbents $[9,12,13]$.

Based on new and restricted environmental regulations, the use of chemicals to combat oil spills might represent another source of marine pollution. These regulations prompted researchers across the globe to search for alternatives to traditional chemicals $[14,15]$. In that view, natural products can be rich alternative sources for several chemicals that have been used in different fields, including medicine, 
industry and nanotechnology. Recently, the biosynthesis of nanomaterials using ecofriendly, nontoxic and low-cost natural materials, such as plant extracts, fungi and biomolecules, have been extensively investigated [16-31]. Since natural materials act as reducing, stabilizing or capping agents during the synthesis of nanoparticles, employing such materials in the final product formation or surface modification steps can provide remarkable results. Many studies have reported the synthesis of magnetic nanoparticles (MNPs) using plant extracts; for instance, Kappaphycus alvarezii whole plant extract, plantain peel extract, a proanthocyanidin seed extract from grapes, Carica papaya and Perilla frutescens leaf extracts [32-36]. In our previous study, asphaltene that was precipitated from crude oil was modified and applied as a natural capping agent for the protection of MNPs from self-aggregation [12]. Anthemis pseudocotula is a member of the genus Anthemis from the Asteraceae family that grows widely in different regions of Saudi Arabia. This plant is a semi-prostrate, dense annual herb with bright, dark-green, feathery leaves and white flowers [37]. To the best of our knowledge, this plant has never been used for the synthesis of nanoparticles. Thus, the hydrophobic components from the aerial parts of this plant extracted by $n$-hexane and chloroform were applied for the biosynthesis of MNPs as capping and stabilizing agents. Furthermore, we evaluated the efficiency of the as-synthesized MNPs in the collection of oil spills using different MNPs:crude oil ratios.

\section{Materials and Methods}

\subsection{Materials}

All reagents that were used to synthesize the MNPs were based on ferrous chloride tetrahydrate $\left(\mathrm{FeCl}_{2} \cdot 4 \mathrm{H}_{2} \mathrm{O} \geq 99 \%\right)$, ferric chloride hexahydrate $\left(\mathrm{FeCl}_{3} \cdot 6 \mathrm{H}_{2} \mathrm{O}, 97 \%\right)$, ammonium hydroxide $(25 \%)$, ethanol, chloroform and $n$-hexane, which were supplied by Aldrich Chemical Co. (Missouri, USA) and were used without any further purification. Saudi heavy crude oil that was produced from the Ras Gara oilfield, Ras Tannora, and seawater that was collected from the western Arabian Gulf at the Saudi coast were used to simulate an oil spill.

\subsection{Preparation of Plant Extracts}

The aerial parts of $A$. pseudocotula were collected from a wild area of Rowdah Khuraim during March 2015 and were then identified by a taxonomist in the herbarium division of King Saud University. The collected fresh parts were chopped into small pieces and were air-dried in the shade. The dried material was extracted sequentially with $n$-hexane and then chloroform three times for $72 \mathrm{~h}$ each at $25{ }^{\circ} \mathrm{C}$. The organic extracts were filtered and concentrated under reduced pressure and temperature conditions. The $n$-hexane and chloroform extracts were abbreviated as APH (A. pseudocotula hexane extract) and APC (A. pseudocotula chloroform extract), respectively.

\subsection{Synthesis of MNPs}

For the synthesis of APH-MNPs and APC-MNPs, $\mathrm{Fe}^{3+}$ and $\mathrm{Fe}^{2+}$ (2:1 Molar ratio, 5.406:1.988 $\mathrm{g}$ of each was dissolved in $100 \mathrm{~mL}$ of deionized water) solutions were added and stirred with the APH or APC solution ( $2 \mathrm{~g}$ dissolved in $100 \mathrm{~mL}$ of ethanol). Then, ammonia solution was added dropwise with continuous stirring at $25^{\circ} \mathrm{C}$. The solution $\mathrm{pH}$ was adjusted to 10 , and the solution was stirred for $1 \mathrm{~h}$ to ensure homogenization and completion of the reaction. The produced APH-MNPs and APC-MNPs were separated easily using an external magnetic field. The MNPs were then washed several times with ethanol, followed by deionized water and, finally, were dried at room temperature.

\subsection{Characterization}

Fourier transform infrared spectroscopic analysis (FTIR; model Nexus 6700 FTIR, Thermo scientific, MN, USA) were used to investigate the functional groups of extracts and the synthesized MNPs. X-ray powder diffraction (XRD; BDX-3300 diffractometer, Beijing University Equipment Manufacturer, China) using $\mathrm{Cu} \mathrm{K} \alpha$ radiation of wavelength $\lambda=1.542{ }^{\circ} \mathrm{A}$ was used to 
analyze the crystal lattice structure of the MNPs. Dynamic light scattering (DLS; Zetasizer 3000HS; Malvern Instruments, Malvern, UK) with a $633 \mathrm{~nm}$ He-Ne laser was applied to determine the particle size, dispersity index and zeta potential of the synthesized MNPs, using ethanol as a solvent. Thermal stability (TGA) of the synthesized MNPs was tested using a Shimadzu, DSC-60 instrument (USA) while heating the MNPs in the range $25-800{ }^{\circ} \mathrm{C}$ under $\mathrm{N}_{2}$ atmosphere at a heating rate of $10{ }^{\circ} \mathrm{C} / \mathrm{min}$. A drop shape analyzer (model DSA-100, Krüss GmbH, Hamburg, Germany) was used to determine the contact angle. For the measurements, a small amount of MNPs was dispersed in ethanol, was spread on the surface of a glass slide, and was evaporated in an oven at $50{ }^{\circ} \mathrm{C}$ to form a thin layer of MNPs on the surface of the slide. The contact angle between seawater and this layer was measured at room temperature. A transmission electron microscope (TEM; JEOL JEM-2100F JEOL, Tokyo, Japan) was used to confirm the surface morphology of the synthesized MNPs. A vibrating sample magnetometer (VSM; LDJ9600 in a field of 20,000 Oe, LDJ Electronics, MI, USA) was used to measure the magnetic parameters of the synthesized MNPs.

\subsection{Application of APH-MNPs and APC-MNPs as Oil Spill Collectors}

In a 500-mL beaker, $1 \mathrm{~mL}$ of Saudi heavy crude oil was poured over $250 \mathrm{~mL}$ of seawater. Different ratios of MNPs to crude oil, ranging from 1:1 to 1:50, were added and mixed slowly with the crude oil over the seawater for $1 \mathrm{~min}$ by using a glass rod. After $5 \mathrm{~min}$, a permanent $\mathrm{Nd}-\mathrm{Fe}-\mathrm{B}$ magnet (4300 Gauss) was used to collect the dispersed crude oil spill. The remaining oil was extracted from the seawater by using chloroform. The efficiency of the MNPs in the collection of the oil spill was calculated using the following equation:

$$
\mathrm{CE}(\%)=V_{0} / V_{1} \times 100
$$

where $V_{0}$ and $V_{1}$ are the volume of the removed and original oil, respectively. The used MNPs were recycled after collecting them with an external magnetic field and washing them several times with chloroform.

\section{Results}

The present work aimed to use the defatted hydrophobic extract APC and APH of A. pseudocotula to apply as capping agents and to increase the hydrophobicity of MNPs with excellent dispersion in crude oil spills more than dispersion in sea water. Moreover, using plant extracts in the synthesis of MNPs increases their economic feasibility as environmentally friendly materials in the aquatic environment. Therefore, the application of the plant extracts to synthesize the nanomaterials was considered as a promising green method due to their biocompatibility, low toxicity and eco-friendly nature because the plants are found in abundance in nature. It was also attempted to characterize the chemical, crystalline structures, morphology, thermal stability, morphology and magnetic properties of the modified MNPs to investigate the effect of the plant extract on the dispersion and stability of MNPs in both aqueous and non-aqueous environments.

\subsection{Chemical Structure of MNPs}

The active functional groups in both (APC and $\mathrm{APH}$ ) extracts and the type of the produced iron oxide to synthesize MNPs (APH-MNPs and APC-MNPs) were investigated by FT-IR (Fourier-transform infrared) analysis, and the results are shown in Figure 1a-d. 

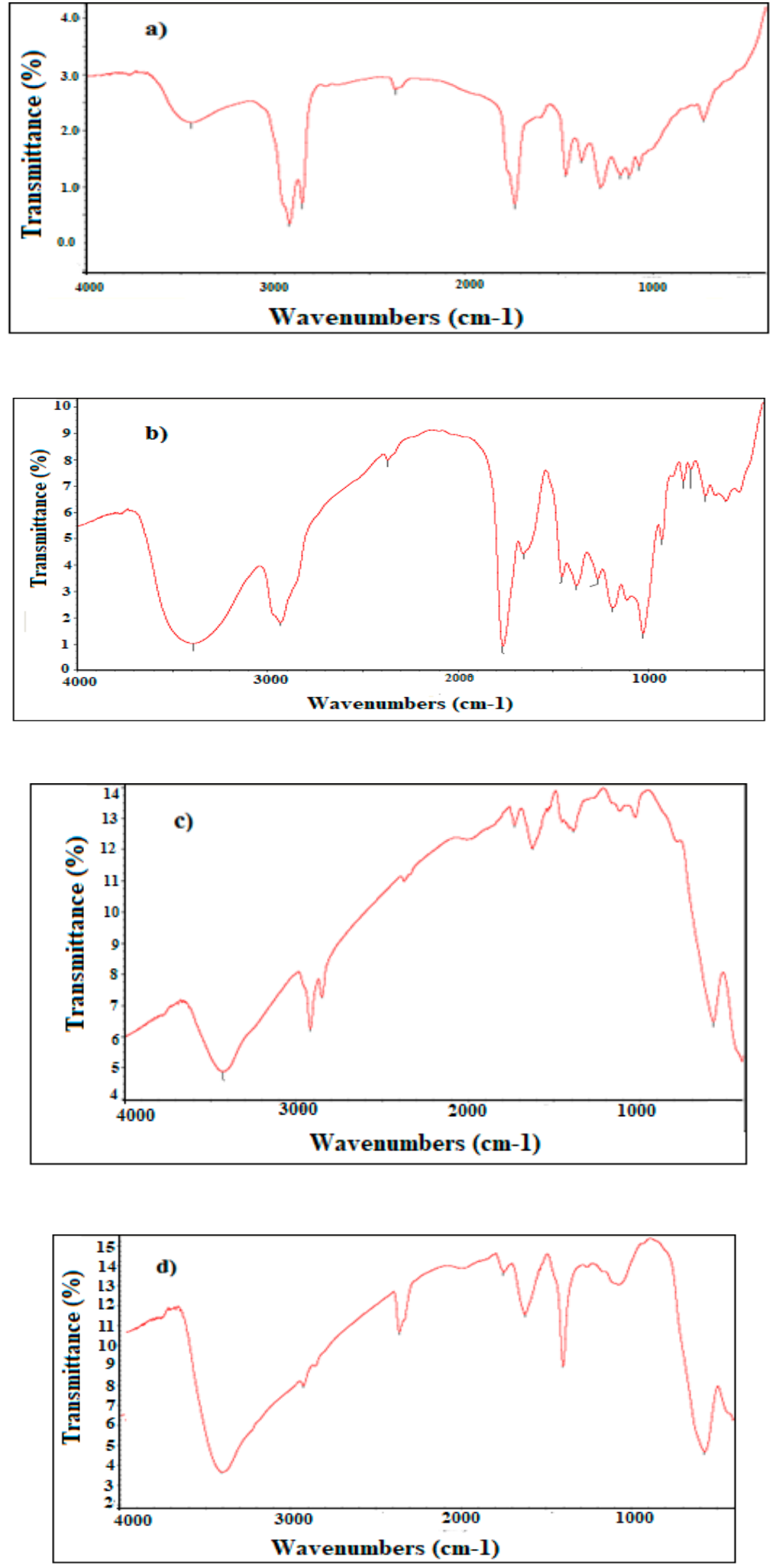

Figure 1. FT-IR (Fourier transform infrared) spectra of (a) APH (n-hexane extract), (b) APC (chloroform extract), (c) APH-MNPS (magnetite nanoparticles) and (d) APC-MNPs.

Figure 2a,b shows the crystalline structure of APH-MNPs and APH-MNCs, respectively using X-ray powder diffraction patterns. 

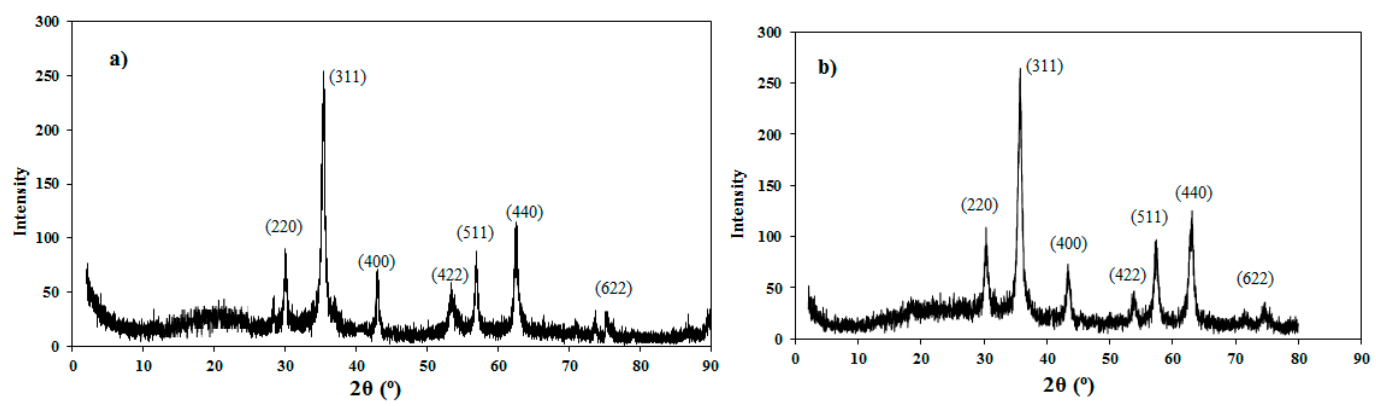

Figure 2. XRD (X-ray powder diffraction) diffraction pattern of (a) APH-MNPs and (b) APC-MNPs.

The surface morphologies of the synthesized APH-MNPs and APC-MNPs that were investigated by TEM are shown in Figure 3a,b.
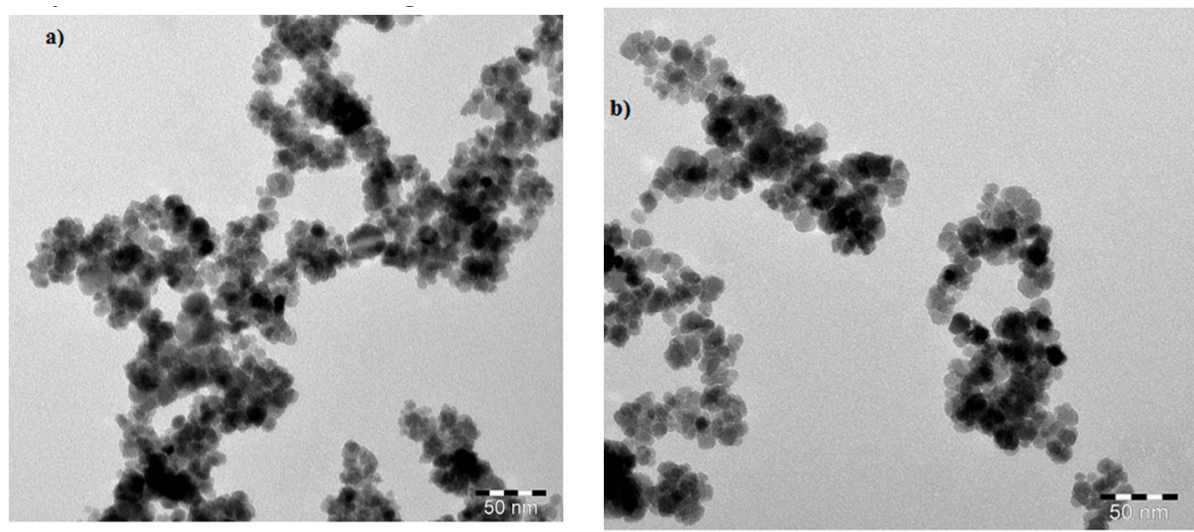

Figure 3. HR-TEM (High-resolution transmission electron microscopy) micrographs of (a) APH-MNPs and (b) APC-MNPs.

The DLS measurements that were applied for the determination of particle diameter, dispersity and zeta potential of the synthesized APH-MNPs and APC-MNPs in ethanol are shown in Figures 4a,b and $5 \mathrm{a}, \mathrm{b}$ and Table 1 .
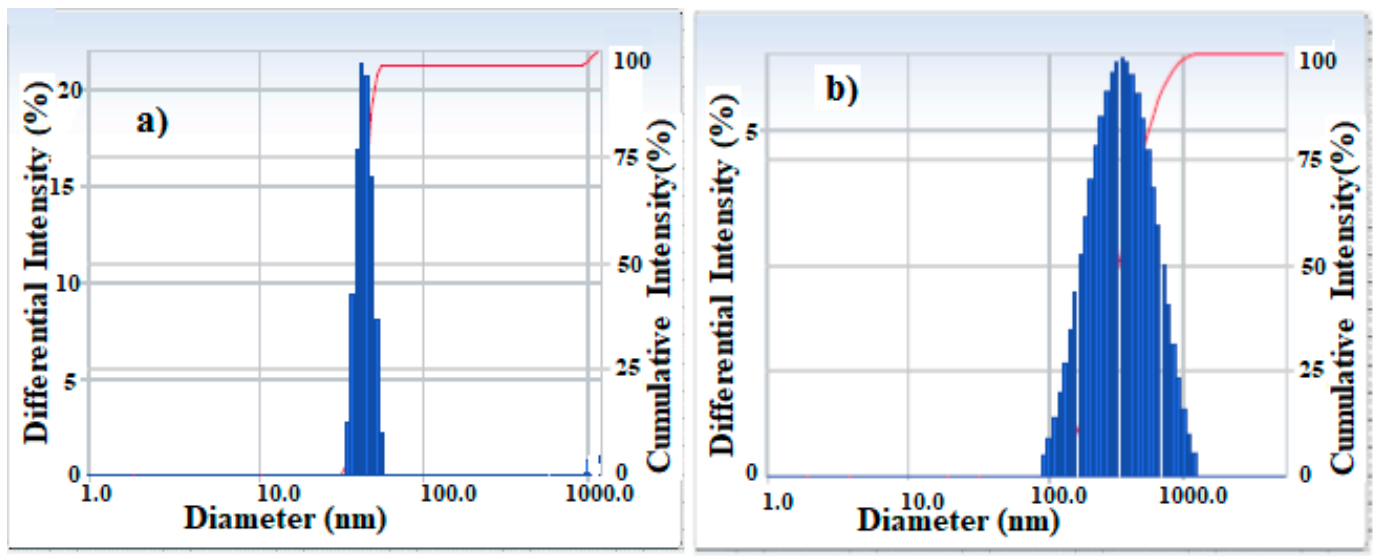

Figure 4. Particle sizes distribution of (a) APH-MNPs and (b) APC-MNPs in ethanol. 

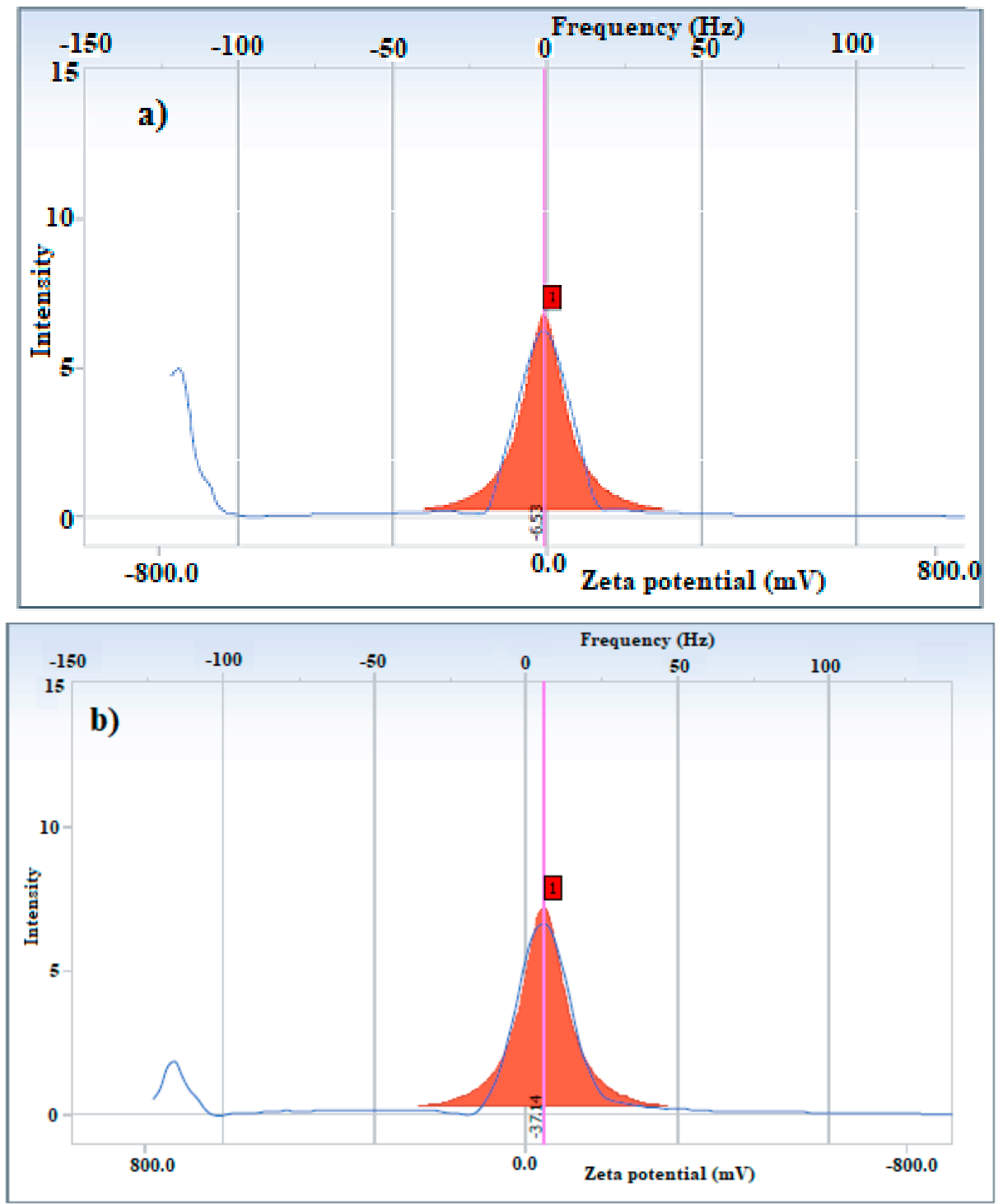

Figure 5. Zeta potential of (a) APH-MNPs and (b) APC-MNPs.

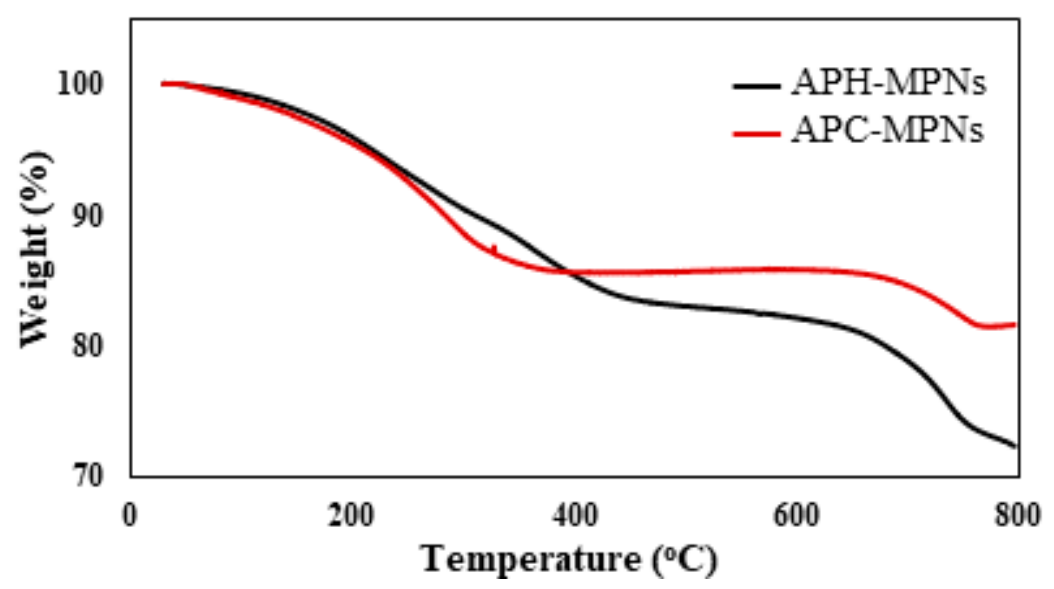

Figure 6. TGA (Thermal gravimetric analysis) thermogram of APH-MNPs and APC-MNPs.

The concentration and thermal stability of MNPs that were incorporated with the biomolecules extracts in the APC and APH were determined using TGA thermograms (Figure 6). 
Table 1. Dynamic light scattering results of APH-MNPs and APC-MNPs at $25{ }^{\circ} \mathrm{C}$.

\begin{tabular}{cccc}
\hline Sample & Particle Size $(\mathbf{n m})$ & Polydispersity Index & Zeta Potential $(\mathbf{m V})$ \\
\hline APH-MNPs & 565.1 & 0.338 & -6.53 \\
APC-MNPs & 308.8 & 0.229 & -37.14 \\
\hline
\end{tabular}

In a general sense, the increasing of MNP's dispersity in crude oil directly increases their efficiency towards the oil spill collection. Such dispersion of MNPs in crude oil is completely influenced by the hydrophobicity of capping agents, and in order to evaluate the hydrophobicity of the synthesized MNPs, the contact angle measurements were performed and are shown in Figure 7a,b.

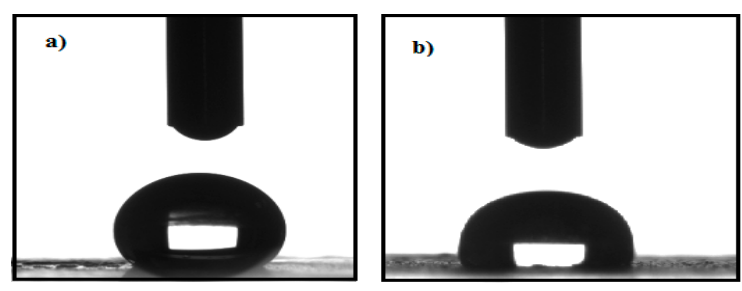

Figure 7. Contact angles of (a) APH-MNPs and (b) APC-MNPs.

The magnetic properties of the synthesized MNPs, represented by the saturation magnetization $\left(M_{S}\right)$, magnetic remanence $\left(M_{r}\right)$ and coercivity $\left(H_{c}\right)$, were determined at room temperature by VSM magnetic hysteresis loops. The results are shown in Figure 8 and in Table 2.

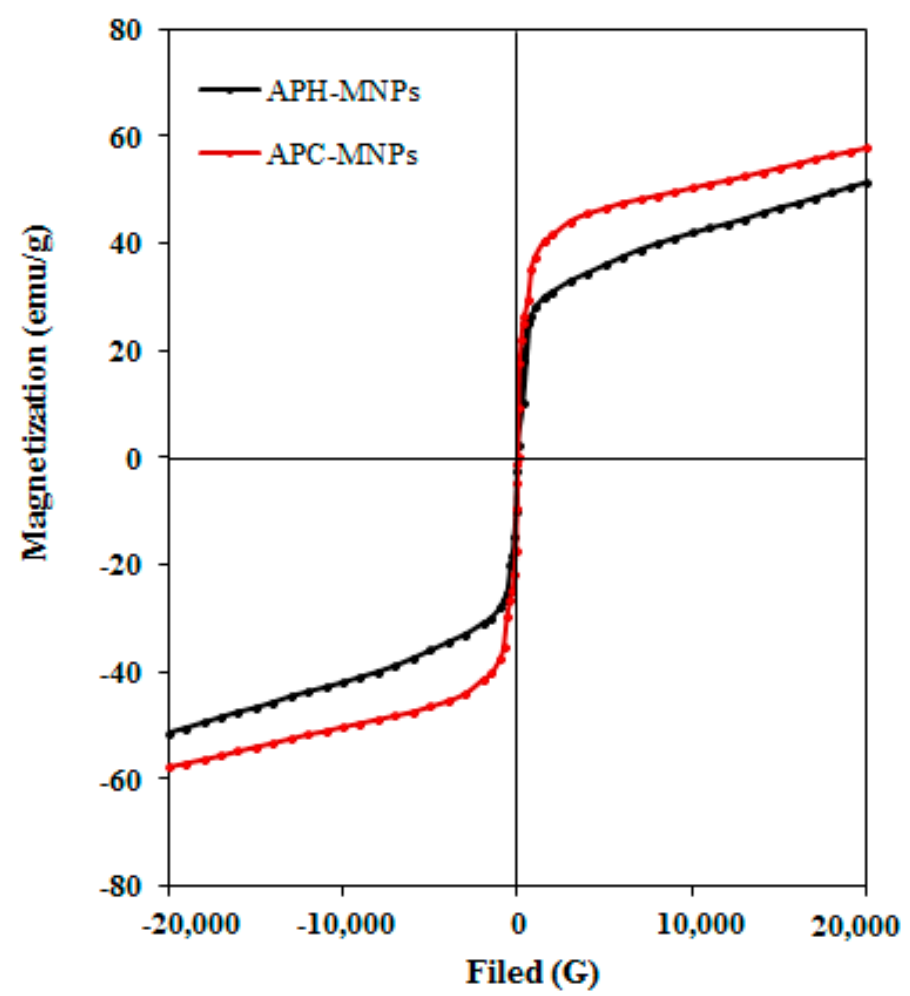

Figure 8. VSM (Vibrating sample magnetometer) hysteresis loop of APH-MNPs and APC-MNPs.

Table 2. Magnetic parameters of APH-MNPs and APC-MNPs at $25^{\circ} \mathrm{C}$.

\begin{tabular}{cccc}
\hline Sample & Ms $(\mathbf{e m u} / \mathrm{g})$ & $\boldsymbol{M r}(\mathbf{e m u} / \mathbf{g})$ & $\boldsymbol{H c}(\mathbf{O e})$ \\
\hline APH-MNPs & 51.42 & 0.153 & 6.4 \\
APC-MNPs & 57.83 & 0.098 & 5.1 \\
\hline
\end{tabular}




\subsection{Efficiency of APH-MNPs and APC-MNPs in the Collection of Oil Spills}

The efficiencies of APH-MNPs and APC-MNPs in the collection of an oil spill of Arabian heavy crude oil was evaluated at different MNPs to crude oil ratios (1:1 to 1:50) and are listed in Table 3.

Table 3. Oil spill collection results.

\begin{tabular}{|c|c|c|c|c|}
\hline Ratio Sample & 1:1 & 1:10 & $1: 25$ & $1: 50$ \\
\hline APH-MNPs & 92 & 90 & 88 & 83 \\
\hline APC-MNPs & 81 & 78 & 74 & 70 \\
\hline
\end{tabular}

The reusability of the synthesized MNPs in the collection of oil spills was tested five times. After the collection of oil using an external magnetic field, the MNPs were washed with chloroform, followed by washing with ethanol and being air-dried, and were then used directly for the next run without further purification. The results for the recovered MNPs (1:10 MNPs to oil ratio) are presented in Figure 9.

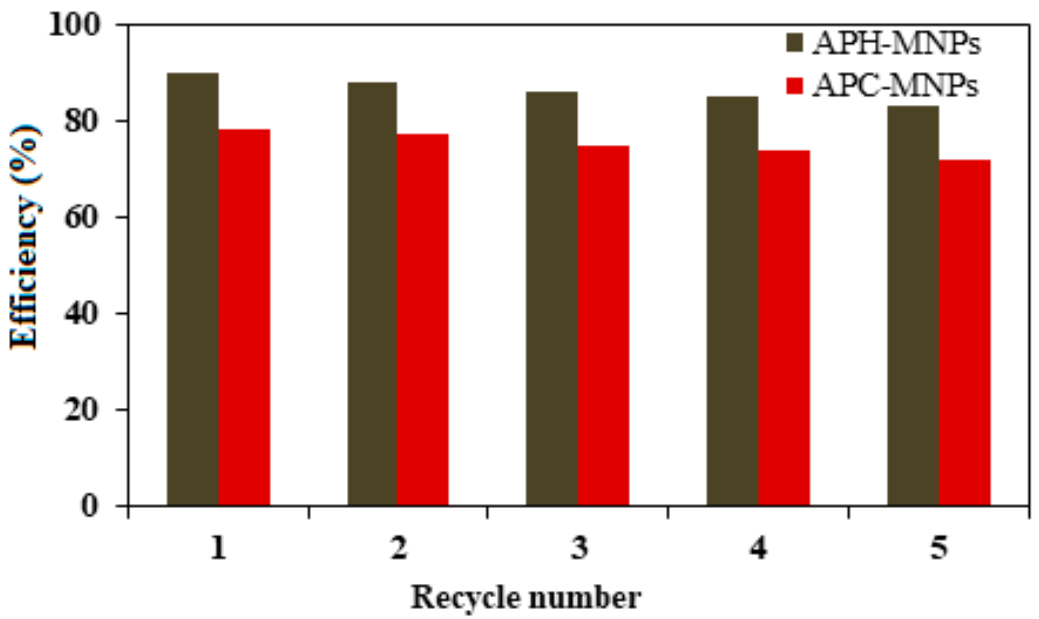

Figure 9. Efficiency of recycled MNPs in the collection of oil spill.

\section{Discussion}

This work is aimed to investigate the efficiency of the green synthesized MNPs for the collection of crude oil in spills. The synthesis of MNPs was achieved using $n$-hexane and chloroform extracts of the aerial parts of $A$. pseudocotula as capping and stabilizing agents to increase the hydrophobic properties of MNPs. The wide availability of this plant, fast extraction process, low cost, green character and diversity of compounds in these extracts ensure their compatibility as capping agents for the MNPs. The $n$-hexane and chloroform extracts usually contain different active compounds, such as fatty acids, sesquiterpenoids, diterpenoids, phenolic compounds, coumarins and terpenoids [38-40]. The presence of these compounds in the capping agent increased their ability to form colloidal particles in the crude oil by utilizing several interactions, such as the aromatic $\pi-\pi^{*}$ stacking force, hydrogen bonding, Van der Waals force and electrostatic attractions. Accordingly, the use of these hydrophobic components as capping agents led to an increase in their dispersion in crude oil rather than seawater and further promoted their ability to collect oil from the surface of the seawater. The co-precipitation method is one of the most common methods that is used in the synthesis of MNPs [12]. Then, the MNPs can be formed via an oxidation and reduction method by using certain reducing agents, such as potassium iodide and sodium sulfite, followed by the addition of ammonium or sodium hydroxide after the removal of the precipitated iodine, as reported in our previous work [12]. In the present study, a mixture of ferric and ferrous ions (2:1 Molar ratio) were hydrolyzed easily in the presence of APH 
or APC, using ammonium hydroxide to form hydrophobic MNPs at room temperature. The overall reaction may be carried out according to the following equations:

$$
\begin{gathered}
\text { A. pseudocutula }+\mathrm{Fe}_{(\mathrm{eq})}^{3+}+\mathrm{Fe}_{(\mathrm{eq})}^{2+}+\mathrm{H}_{2} \mathrm{O} \stackrel{\text { Stirring }}{\longrightarrow}\left(\text { A. pseudocutula } / \mathrm{Fe}^{3+}-\mathrm{Fe}^{2+}\right) \\
\left(\text { A. pseudocutula } / \mathrm{Fe}^{3+}-\mathrm{Fe}^{2+}\right)+8 \mathrm{OH}_{(\mathrm{aq})} \stackrel{\text { Stirring }}{\longrightarrow}\left(\text { A. pseudocutula } / \mathrm{Fe}_{3} \mathrm{O}_{4}\right)_{\mathrm{s}} \downarrow \downarrow+4 \mathrm{H}_{2} \mathrm{O}_{(\mathrm{aq})}
\end{gathered}
$$

Magnetite can interact by complexation with heteroatoms such as oxygen and nitrogen that are present in the APC and APH extracts. The capping process might have taken place through a physical interaction, such as hydrogen bonding, Van der Waals, electrostatic attractions and/or polarity induction forces between the formed nanoparticles and various functional groups of phytomolecules that are present in APH and APC extracts [41]. The functional groups of the extracts (APH and APC) and the capped MNPs (APH-MNPs and APC-MNPs) were determined by FTIR spectra (Figure 1a-d), and the $\mathrm{C}-\mathrm{H}$ stretching and bending vibrations of the aliphatic groups $\left(\mathrm{CH}_{3}-\right.$ and $\left.-\mathrm{CH}_{2}-\right)$ in the APH (Figure 1a) were observed at $2933 \mathrm{~cm}^{-1}, 2856 \mathrm{~cm}^{-1}, 1460 \mathrm{~cm}^{-1}$ and $1453 \mathrm{~cm}^{-1}$. Similarly, the appearance of bands at $3413 \mathrm{~cm}^{-1}$ and $1733 \mathrm{~cm}^{-1}$ indicated the presence of stretching vibrations of the polar functional groups $-\mathrm{NH},-\mathrm{OH}$ and $-\mathrm{C}=\mathrm{O}$, respectively. The same bands were appeared in the APH-MNPs spectrum (Figure 1c) indicating functionalization of these functional groups with MNPs. The appearance of a new band (Figure 1c) at $572 \mathrm{~cm}^{-1}$ (Fe-O stretching) confirms the formation of MNPs (magnetite) only without any other iron oxides. In the same way, the APC spectrum (Figure 1b) showed bands at $3413 \mathrm{~cm}^{-1}, 2926 \mathrm{~cm}^{-1}, 1748 \mathrm{~cm}^{-1}$ and $1402 \mathrm{~cm}^{-1}$ that referred to stretching and bending vibrations of $-\mathrm{OH},-\mathrm{CH}_{2}$ and $-\mathrm{C}=\mathrm{O}$. In addition, the appearance of other bands in the APC at $3139 \mathrm{~cm}^{-1}, 1654 \mathrm{~cm}^{-1}$ and $2361 \mathrm{~cm}^{-1}$ was attributed to aliphatic $=\mathrm{C}-\mathrm{H}, \mathrm{C}=\mathrm{C}$ and amide bonding, respectively. These active functional groups in the APC spectrum appeared also in the APC-MNPs spectrum (Figure 1d) with an appearance characteristic band of MNPs at $572 \mathrm{~cm}^{-1}$. An increase in the intensity of this band with capped MNPs in both samples (APH-MNPs and APC-MNPs) indicates an increase in the concentration of the MNPs. Moreover, a shift in the bands positions and decrease in the intensity of the functional groups in APH-MNPs and APC-MNPs (Figure 1b,c) also provides evidence for the successful bonding of MNPs with APH and APC functional groups. XRD diffractograms (Figure 2a,b) are used to investigate the iron oxide types beside the crystalline structure of MNPs [12]. The data (Figure 2a,b) showed several characteristic peaks at $2 \theta$ values of $30.13^{\circ}(220)$, $35.48^{\circ}(311), 43.15^{\circ}(400), 53.95^{\circ}(422), 57.03^{\circ}(511), 62.62^{\circ}(440)$ and $74.52^{\circ}(622)$. These peaks were compared with the standard peaks in the Joint Committee on Powder Diffraction Standards (JCPDS) file (PDF No. 65-3107), and it was confirmed that the crystal structure of the MNPs was not affected by the modification of their surfaces with APC and APH components. The XRD patterns of MNPs (Figure 2a,b) elucidate the absence of diffraction peaks, i.e., amorphous nature, except for the observed broad band at $2 \theta$ values $\left(20^{\circ}-30^{\circ}\right)$. The broad diffraction peaks (Figure $\left.2 a, b\right)$ appearing at $22.1^{\circ}$ can be attributed to the presence of APH and APC phytomolecules, providing indirect evidence for the successful coating of the MNPs with APH and APC phytomolecules. Generally, the amorphous nature of the particles is non-toxic to living organisms and hence, amorphous herbal nanoparticles enhance the biocompatibility for different environmental applications [42]. XRD diffractograms were also used to estimate the average particle size of APH-MNPs and APC-MNPs by the Deybye-Scherrer equation. This equation depends on the relationship between particle size and broadening of the XRD peak and can be represented by the following equation:

$$
\mathrm{PS}=\mathrm{K} \lambda(\beta \operatorname{COS} \theta)
$$

where PS is the particle size, $\mathrm{K}$ is a dimensionless shape factor called Scherrer constant $(0.9), \lambda$ is the wavelength of X-ray $(0.15406 \mathrm{~nm}), \beta$ is the width of the XRD peak at half the maximum intensity and $\theta$ is the Bragg diffraction angle. Using this equation, the average particle size of APH-MNPs and APC-MNPs were found to be 11-19 nm. The TEM micrographs of APH-MNPs and APC-MNPs 
(Figure 3a,b) elucidate the appearance of the MNPs in the cluster form which attributed to the magnetic behavior where the surface charges and magnetic forced them to be aggregated [9]. From DLS data (Figure 4a,b), the average diameter and polydispersity index (PDI) were found to be $565.1 \mathrm{~nm}$ and 0.338 , respectively, for the APH-MNPs and $308.8 \mathrm{~nm}$ and 0.229 , respectively, for the APC-MNPs in ethanol. However, considerable differences in the particle diameter as measured by TEM and DLS reflected the inclusion of agglomerated regions in DLS measurement that depends on the behavior of particles in the solution. Moreover, the average particle size that was obtained from the Scherrer equation supported the TEM results. Notably, the APH-MNPs were more agglomerated than the corresponding APC-MNPs, which might be caused by the Van der Waals attraction forces between the hydrophobic surfaces between these particles [43]. The small values of PDI confirms the formation of monodispersed MNPs that reflects the efficiency of APH and APC components as capping and stabilizing agents. The zeta potential of the APC-MNPs (Figure 6a,b) seemed to have a more negative value $(-37.14 \mathrm{mV}$ ) than that of the AHP-MNPs $(-6.53 \mathrm{mV})$, which further indicated the higher dispersity and stability of the APC-MNPs in ethanol as compared with the APH-MNPs. The concentration of the formed nanoparticles is determined from TGA thermograms (Figure 6). The magnetite contents of APH-MNPs and APC-MNPs were $72.5 \%$ and $81.5 \%$, respectively, as determined at $800{ }^{\circ} \mathrm{C}$. This indicated that there was a higher amount of capping agent on the APH-MNPs composite than the corresponding APC-MNPs composite. The data also elucidated that the degradation process seemed to have occurred at two different temperature regions, i.e., $100-400{ }^{\circ} \mathrm{C}$ and $670-780{ }^{\circ} \mathrm{C}$. In the first region (100-400 $\left.{ }^{\circ} \mathrm{C}\right)$, the APH-MNPs and APC-MNPs lost around $14 \%$ and $15 \%$ of their initial weights, respectively, and the losses could be ascribed to the decomposition of APH and APC groups. However, the weight losses in the second region were $10 \%$ and 3.5\% for the APH-MNPs and APC-MNPs, respectively. The high thermal stability of APC-MNPs at the degradation temperature ranged from $400{ }^{\circ} \mathrm{C}$ to $700{ }^{\circ} \mathrm{C}$, which might reflect stronger interactions between the relatively polar components of APC as compared with those of APH.

It was observed during the experimental studies that the synthesized MNPs exhibited no easy dispersion in seawater, while high dispersion was observed in toluene, xylene, chloroform and other low polarity solvents. The hydrophobicity of the prepared MNPs can be investigated from the contact angles measurements as represented in Figure 7. The data elucidated that the contact angles of APH-MNP and APC-MNP composites are $142^{\circ}$ and $118^{\circ}$, respectively, which reflected the higher hydrophobic content of APH extract as compared against the APC extract. This means the formation of superhydrophobic capping of MNPs in the presence of APH extracts [42]. The magnetization curves for APH-MNPs and APC-MNPs composites (Figure 8) also indicate the superparamagnetic behavior. In addition, from the analysis, we observed an increased value for $M_{S}$ and decreased values for $M_{r}$ and $H_{c}$ as compared to other MNPs that were capped by different biocomponents [44,45]. The increase in the $M_{S}$ value of APC-MNPs reflected the lower amount of capping agent as compared with APH-MNPs, which was confirmed by the TGA analysis (Figure 6).

The contact angles measurements and magnetic properties of the synthesized MNPs show that increasing their hydrophobicity and supermagnetic nature make them suitable candidates in the collection of oil spills. Therefore, the efficiencies of different ratios of APH-MNPs and APC-MNPs as oil spill collectors for different MNPs: heavy crude oil ratios, from 1:1 up to 1:50 were evaluated. It is observed from the analysis that the best ratio of APH-MNPs:crude oil that succeeded in removing $90 \%$ of the crude oil was 1:10. In addition, the APH-MNPs were demonstrated to be highly efficient for the removal of crude oil in comparison to the corresponding APC-MNPs composite (only 78\%). The observed high efficiency of APH-MNPs as compared to APC-MNPs reflected the greater hydrophobicity of the capping agent, which helped to increase its dispersion in crude oil, as confirmed by the contact angle measurements (Figure 7). Consequently, the efficiency of MNPs towards the collection of oil spills can be significantly improved by increasing the hydrophobicity of the capping agents. Moreover, the oil spill collection efficiency did not improve significantly by simply increasing the ratio of MNPs:crude oil to 1:1 because the MNPs could aggregate easily and, thus, 
formed aggregated clusters that disturbed the magnetic attractions between the MNPs and the external magnetic field. As observed in Figure 9, the efficiency of the recovered particles in the collection of the oil spill seemed to have decreased slightly with an increased number of cycles, indicating that the polarity changed as the material was reused.

\section{Conclusions}

In summary, hydrophobic MNPs could be synthesized in a novel, inexpensive, non-toxic and eco-friendly approach where the hydrophobic biocomponents extracted from A. pseudocotula were employed as capping agents. The surface functionality of these biocomponents with MNPs (APH-MNPs and APC-MNPs) and the persistence of the nanoparticles at all stages were confirmed by FT-IR analysis. The contact angle measurements provided proof for the effective dispersion of the synthesized MNPs in crude oil rather than in the water medium. The microstructures of the particles were supported by the TEM and DLS analyses where the particles were observed to be spherical in shape with an average diameter of $565 \mathrm{~nm}$ (APH-MNPs) and $308 \mathrm{~nm}$ (APC-MNPs). The superparamagnetic behavior was observed by the magnetic studies where the highest magnetization value was observed for the APC-MNPs as against the APH-MNPs. Such a decrease could be linked to the hydrophobic behavior. Furthermore, the APH-MNPs were demonstrated to be efficient for the collection of crude oil as compared against the APC-MNPs due to its higher dispersion ability in crude oil. Finally, the MNPs could be reused at least five times with no or slight loss of efficiency. Hence, by considering the simplicity of our synthesis method in addition to the wide availability of plant extract as a source for hydrophobic capping agents, the formed MNP-based composites can serve as potential platforms for the separation of oils from spills during seashore drilling operations.

\section{Patents}

Mahmood M.S. Abdullah, Ayman M. Atta, Hamad A. Al-Lohedan, Hamad Z. Alkhathlan, Merajuddin Khan, Abdulrahman O. Ezzat, Biosynthesized magnetic metal nanoparticles for oil spill remediation, Patent number: 9901903 USA(2018).

Author Contributions: Methodology, investigation, writing-review and editing, M.M.S.A. and A.M.A.; Supervision, H.A.A.; Revision and resources, H.Z.A.; Data curation, M.K.; Validation, A.O.E.

Funding: This research was funded by Deanship of Scientific Research at King Saud University, grant number RG-235.

Acknowledgments: The authors extend their appreciation to the Deanship of Scientific Research at King Saud University for funding this work through research group No. (RG- 235).

Conflicts of Interest: The authors declare no conflict of interest.

\section{References}

1. Chapman, H.; Purnell, K.; Law, R.J.; Kirby, M.F. The use of chemical dispersants to combat oil spills at sea: A review of practice and research needs in Europe. Mar. Pollut. Bull. 2007, 54, 827-838. [CrossRef] [PubMed]

2. Etkin, D.S. Estimating cleanup costs for oil spills. Proceedings of International oil spill conference, Arlington, MA, USA, 8-11 March 1999; pp. 35-39.

3. Fingas, M. Oil Spill Science and Technology, 2nd ed.; Gulf professional publishing: Edmonton, AB, Canada, 2016.

4. Balba, M.; Al-Awadhi, N.; Al-Daher, R. Bioremediation of oil-contaminated soil: Microbiological methods for feasibility assessment and field evaluation. J. Microbiol. Meth. 1998, 32, 155-164. [CrossRef]

5. Oribayo, O.; Feng, X.; Rempel, G.L.; Pan, Q. Modification of formaldehyde-melamine-sodium bisulfite copolymer foam and its application as effective sorbents for clean up of oil spills. Chem. Eng. Sci. 2017, 160, 384-395. [CrossRef]

6. Cojocaru, C.; Pricop, L.; Samoila, P.; Rotaru, R.; Harabagiu, V. Surface hydrophobization of polyester fibers with poly(methylhydro-dimethyl) siloxane copolymers: Experimental design for testing of modified nonwoven materials as oil spill sorbents. Polym. Test. 2017, 59, 377-389. [CrossRef] 
7. Cojocaru, C.; Dorneanu, P.P.; Airinei, A.; Olaru, N.; Samoila, P.; Rotaru, A. Design and evaluation of electrospun polysulfone fibers and polysulfone $/ \mathrm{NiFe}_{2} \mathrm{O}_{4}$ nanostructured composite as sorbents for oil spill cleanup. J. Taiwan Inst. Chem. Eng. 2017, 70, 267-281. [CrossRef]

8. Rongsayamanont, W.; Soonglerdsongpha, S.; Khondee, N.; Pinyakong, O.; Tongcumpou, C.; Sabatini, D.A.; Luepromchai, E. Formulation of crude oil spill dispersants based on the HLD concept and using a lipopeptide biosurfactant. J. Hazard. Mater. 2017, 334, 168-177. [CrossRef] [PubMed]

9. Atta, A.M.; Ezzat, A.O.; Hashem, A.I. Synthesis and application of monodisperse hydrophobic magnetite nanoparticles as an oil spill collector using an ionic liquid. RSC Adv. 2017, 7, 16524-16530. [CrossRef]

10. Atta, A.M.; Al-Lohedan, H.A.; Abdullah, M.M.; ElSaeed, S.M. Application of new amphiphilic ionic liquid based on ethoxylated octadecylammonium tosylate as demulsifier and petroleum crude oil spill dispersant. J. Ind. Eng. Chem. 2016, 33, 122-130. [CrossRef]

11. Abullah, M.M.; Al-Lohedan, H.A.; Attah, A.M. Synthesis and application of amphiphilic ionic liquid based on acrylate copolymers as demulsifier and oil spill dispersant. J. Mol. Liq. 2016, 219, 54-62. [CrossRef]

12. Abdullah, M.M.; Al-Lohedan, H.A.; Atta, A.M. Novel magnetic iron oxide nanoparticles coated with sulfonated asphaltene as crude oil spill collectors. RSC Adv. 2016, 6, 59242-59249. [CrossRef]

13. Atta, A.M.; Al-Lohedan, H.A.; Al-Hussain, S.A. Functionalization of magnetite nanoparticles as oil spill collector. Int. J. Mol. Sci. 2015, 16, 6911-6931. [CrossRef] [PubMed]

14. Clark, J.H.; Budarin, V.; Deswarte, F.E.; Hardy, J.J.; Kerton, F.M.; Hunt, A.J.; Luque, R.; Macquarrie, D.J.; Milkowski, K.; Rodriguez, A. Green chemistry and the biorefinery: a partnership for a sustainable future. Green Chem. 2006, 8, 853-860. [CrossRef]

15. Anastas, P.T.; Warner, J.C. Green Chemistry: Theory and Practice; Oxford University Press: New York, NY, USA, 1998; p. 30.

16. Shankar, S.; Jaiswal, L.; Aparna, R.; Prasad, R. Synthesis, characterization, in vitro biocompatibility, and antimicrobial activity of gold, silver and gold silver alloy nanoparticles prepared from Lansium domesticum fruit peel extract. Mater. Lett. 2014, 137, 75-78. [CrossRef]

17. Mittal, A.K.; Chisti, Y.; Banerjee, U.C. Synthesis of metallic nanoparticles using plant extracts. Biotechnol. Adv. 2013, 31, 346-356. [CrossRef] [PubMed]

18. Makarov, V.; Love, A.; Sinitsyna, O.; Makarova, S.; Yaminsky, I.; Taliansky, M.; Kalinina, N. "Green” nanotechnologies: synthesis of metal nanoparticles using plants. Acta Nat. 2014, 6, 35-44.

19. Kuppusamy, P.; Yusoff, M.M.; Maniam, G.P.; Govindan, N. Biosynthesis of metallic nanoparticles using plant derivatives and their new avenues in pharmacological applications-An updated report. Saudi Pharm. J. 2016, 24, 473-484. [CrossRef] [PubMed]

20. Chung, I.-M.; Park, I.; Seung-Hyun, K.; Thiruvengadam, M.; Rajakumar, G. Plant-mediated synthesis of silver nanoparticles: Their characteristic properties and therapeutic applications. Nanoscale Res. Lett. 2016, 11, 40. [CrossRef] [PubMed]

21. Ankamwar, B.; Chaudhary, M.; Sastry, M. Gold nanotriangles biologically synthesized using tamarind leaf extract and potential application in vapor sensing. Synth. React. Inorg. Met. 2005, 35, 19-26. [CrossRef]

22. Ahmed, S.; Ahmad, M.; Swami, B.L.; Ikram, S. A review on plants extract mediated synthesis of silver nanoparticles for antimicrobial applications: a green expertise. J. Adv. Res. 2016, 7, 17-28. [CrossRef] [PubMed]

23. Thakkar, K.N.; Mhatre, S.S.; Parikh, R.Y. Biological synthesis of metallic nanoparticles. Nanomed. NBM 2010, 6, 257-262. [CrossRef] [PubMed]

24. Mukherjee, P.; Senapati, S.; Mandal, D.; Ahmad, A.; Khan, M.I.; Kumar, R.; Sastry, M. Extracellular synthesis of gold nanoparticles by the fungus Fusarium oxysporum. ChemBioChem 2002, 3, 461-463. [CrossRef]

25. Gajbhiye, M.; Kesharwani, J.; Ingle, A.; Gade, A.; Rai, M. Fungus-mediated synthesis of silver nanoparticles and their activity against pathogenic fungi in combination with fluconazole. Nanomed. NBM 2009, 5, 382-386. [CrossRef] [PubMed]

26. Bhainsa, K.C.; D'souza, S. Extracellular biosynthesis of silver nanoparticles using the fungus Aspergillus fumigatus. Colloids Surf. B Biointerfaces 2006, 47, 160-164. [CrossRef] [PubMed]

27. Ahmad, A.; Mukherjee, P.; Senapati, S.; Mandal, D.; Khan, M.I.; Kumar, R.; Sastry, M. Extracellular biosynthesis of silver nanoparticles using the fungus Fusarium oxysporum. Colloids Surf. B Biointerfaces 2003, 28, 313-318. [CrossRef] 
28. Polavarapu, L.; Xu, Q.-H. A single-step synthesis of gold nanochains using an amino acid as a capping agent and characterization of their optical properties. Nanotechnology 2008, 19, 075601. [CrossRef] [PubMed]

29. Huang, P.; Pandoli, O.; Wang, X.; Wang, Z.; Li, Z.; Zhang, C.; Chen, F.; Lin, J.; Cui, D.; Chen, X. Chiral guanosine $5^{\prime}$-monophosphate-capped gold nanoflowers: Controllable synthesis, characterization, surface-enhanced Raman scattering activity, cellular imaging and photothermal therapy. Nano Res. 2012, 5, 630-639. [CrossRef]

30. Hendler, N.; Fadeev, L.; Mentovich, E.D.; Belgorodsky, B.; Gozin, M.; Richter, S. Bio-inspired synthesis of chiral silver nanoparticles in mucin glycoprotein—the natural choice. Chem. Commun. 2011, 47, 7419-7421. [CrossRef] [PubMed]

31. Bhumkar, D.R.; Joshi, H.M.; Sastry, M.; Pokharkar, V.B. Chitosan reduced gold nanoparticles as novel carriers for transmucosal delivery of insulin. Pharm. Res. 2007, 24, 1415-1426. [CrossRef] [PubMed]

32. Yew, Y.P.; Shameli, K.; Miyake, M.; Kuwano, N.; Khairudin, N.B.B.A.; Mohamad, S.E.B.; Lee, K.X. Green synthesis of magnetite $\left(\mathrm{Fe}_{3} \mathrm{O}_{4}\right)$ nanoparticles using seaweed (Kappaphycus alvarezii) extract. Nanoscale Res. Lett. 2016, 11, 276. [CrossRef] [PubMed]

33. Venkateswarlu, S.; Rao, Y.S.; Balaji, T.; Prathima, B.; Jyothi, N. Biogenic synthesis of $\mathrm{Fe}_{3} \mathrm{O}_{4}$ magnetic nanoparticles using plantain peel extract. Mater. Lett. 2013, 100, 241-244. [CrossRef]

34. Narayanan, S.; Sathy, B.N.; Mony, U.; Koyakutty, M.; Nair, S.V.; Menon, D. Biocompatible magnetite/gold nanohybrid contrast agents via green chemistry for MRI and CT bioimaging. ACS Appl. Mater. Interfaces 2011, 4, 251-260. [CrossRef] [PubMed]

35. Latha, N.; Gowri, M. Biosynthesis and characterisation of $\mathrm{Fe}_{3} \mathrm{O}_{4}$ nanoparticles using Caricaya papaya leaves extract. Int. J. Sci. Res. 2014, 3, 1551-1556.

36. Basavegowda, N.; Mishra, K.; Lee, Y.R. Sonochemically synthesized ferromagnetic $\mathrm{Fe}_{3} \mathrm{O}_{4}$ nanoparticles as a recyclable catalyst for the preparation of pyrrolo[3,4-c]quinoline-1,3-dione derivatives. RSC Adv. 2014, 4, 61660-61666. [CrossRef]

37. Collenette, S. Illustrated Guide to the Flowers of Saudi Arabia; Scorpion: FLINT, UK, 1985.

38. Musa, A.M.; Ibrahim, M.A.; Aliyu, A.B.; Abdullahi, M.S.; Tajuddeen, N.; Ibrahim, H.; Oyewale, A.O. Chemical composition and antimicrobial activity of hexane leaf extract of Anisopus mannii (Asclepiadaceae). J. Intercult. Ethnopharmacol. 2015, 4, 129. [CrossRef] [PubMed]

39. Hossain, M.A.; Al-Toubi, W.A.; Weli, A.M.; Al-Riyami, Q.A.; Al-Sabahi, J.N. Identification and characterization of chemical compounds in different crude extracts from leaves of Omani neem. J. Taibah Univ. Sci. 2013, 7, 181-188. [CrossRef]

40. Azwanida, N. A review on the extraction methods use in medicinal plants, principle, strength and limitation. Med. Aromat. Plants 2015, 4, 3-8.

41. Reimers, J.R.; Ford, M.J.; Marcuccio, S.M.; Ulstrup, J.; Hush, N.S. Competition of van der Waals and chemical forces on gold-sulfur surfaces and nanoparticles. Nat. Rev. Chem. 2017, 1, 0017. [CrossRef]

42. Karthik, S.; Suriyaprabha, R.; Vinoth, M.; Srither, S.R.; Manivasakan, P.; Rajendran, V.; Valiyaveettil, S. Larvicidal, super hydrophobic and antibacterial properties of herbal nanoparticles from Acalypha indica for biomedical applications. RSC Adv. 2017, 7, 41763-41770.

43. Attard, P. Long-range attraction between hydrophobic surfaces. J. Phys. Chem. 1989, 93, 6441-6444. [CrossRef]

44. Phumying, S.; Labuayai, S.; Thomas, C.; Amornkitbamrung, V.; Swatsitang, E.; Maensiri, S. Aloe vera plant-extracted solution hydrothermal synthesis and magnetic properties of magnetite $\left(\mathrm{Fe}_{3} \mathrm{O}_{4}\right)$ nanoparticles. Appl. Phys. A 2013, 111, 1187-1193. [CrossRef]

45. Abdeen, M.; Sabry, S.; Ghozlan, H.; El-Gendy, A.A.; Carpenter, E.E. Microbial-physical synthesis of Fe and $\mathrm{Fe}_{3} \mathrm{O}_{4}$ magnetic nanoparticles using Aspergillus niger YESM1 and supercritical condition of ethanol. J. Nanomater. 2016, 2016, 9174891. [CrossRef]

(C) 2018 by the authors. Licensee MDPI, Basel, Switzerland. This article is an open access article distributed under the terms and conditions of the Creative Commons Attribution (CC BY) license (http://creativecommons.org/licenses/by/4.0/). 